\title{
THE COMPREHESIVE EVALUATION METHOD AT PROFESSOR'S LEVEL IN CHINESE UNIVERSITY
}

\author{
Wu Yuhua \\ (Tianjin University) \\ Zheng Zhongsan \\ (Nankai University: \\ Chen Zegan \\ (Transport Engineering College;
}

\begin{abstract}
How to evaluate and assess the work done by a professor is very important in the management of university. This paper, first, set up an index system of evaluation at several levels, then uses the multilobjective decision making method (AHP) to quantify the evaluation criteria. Finally. from the view point of value engineering gives a new concept of value coefficient of a professor.
\end{abstract}

1. Introduction.

How to evaluate and assess the work done by a professor is very important in the management of a unitersity. The development program of a university, promotion of personnel and distributing bonus are all needed to be based on such an evaluation or assessment. The motivation of individuals can be stimulated only when the evaluation in consistence with promotion and exprisal. Therefore. how to evaluate the work done by a professor objectively, and scientifically becomes an urgent problem to be solved.

There are two aspects in the topic of evaluating the job of a professor. First, we need a suitable organization to do the job, this can be done by the academic-cominittee headed by chairman of each of the departments. Second, we need a group of reasonable criteria. obtained by systematic analysis on the work by all teachers to assess quantitative indexes for each individual.

From the view point of value engineering, the problem of evaluating individual professor's job is to assess the functional coefficient for each of them - evaluation criteria. This paper. first. sets up a system of evaluation criteria at several levels. then uses the multi-goal decision making method incorporate with qualitative and quantitative analysis to quantify the evaluation criteria. Finally, the paper gives the concept of value coefficient, in evaluating we should not only. focus on the criteria mentioned above but also consider magnitute of the coefficient. from the economic point of view to consider the ratio of quantified evaluation index to "salary.

\section{The Evaluation Criteria at Several Levels.}

To set up such a criteria system we should follow the following three principles.

51) the criteria should be consistent with national policies and regulations.

(2) The system should be comprehesive, reasonable and scientific.

:3: The system should be relatively simple and has the comparability and measurablity. 
The university in our country involving both teaching and academic researches so the evaluation criteria should reflect the work of both. We can change the teaching and researching into more specific activities and for each of the activities we may stepwise further. For instance. for teaching. it could be divided into two parts: guality and quantity. for quantity of teaching. it can be further divided into four parts: average annual teaching hours, number of courses given to graduatestudents. number of courses given to undergratuated studens, number of graduate students advised. Same for the researching work, it can be expressed by papers and books published, and other research projects full filled. By this idea, we can set up an evaluation indexes system in three levels and which haye 14 different indicators. This is shown in the following diagram.

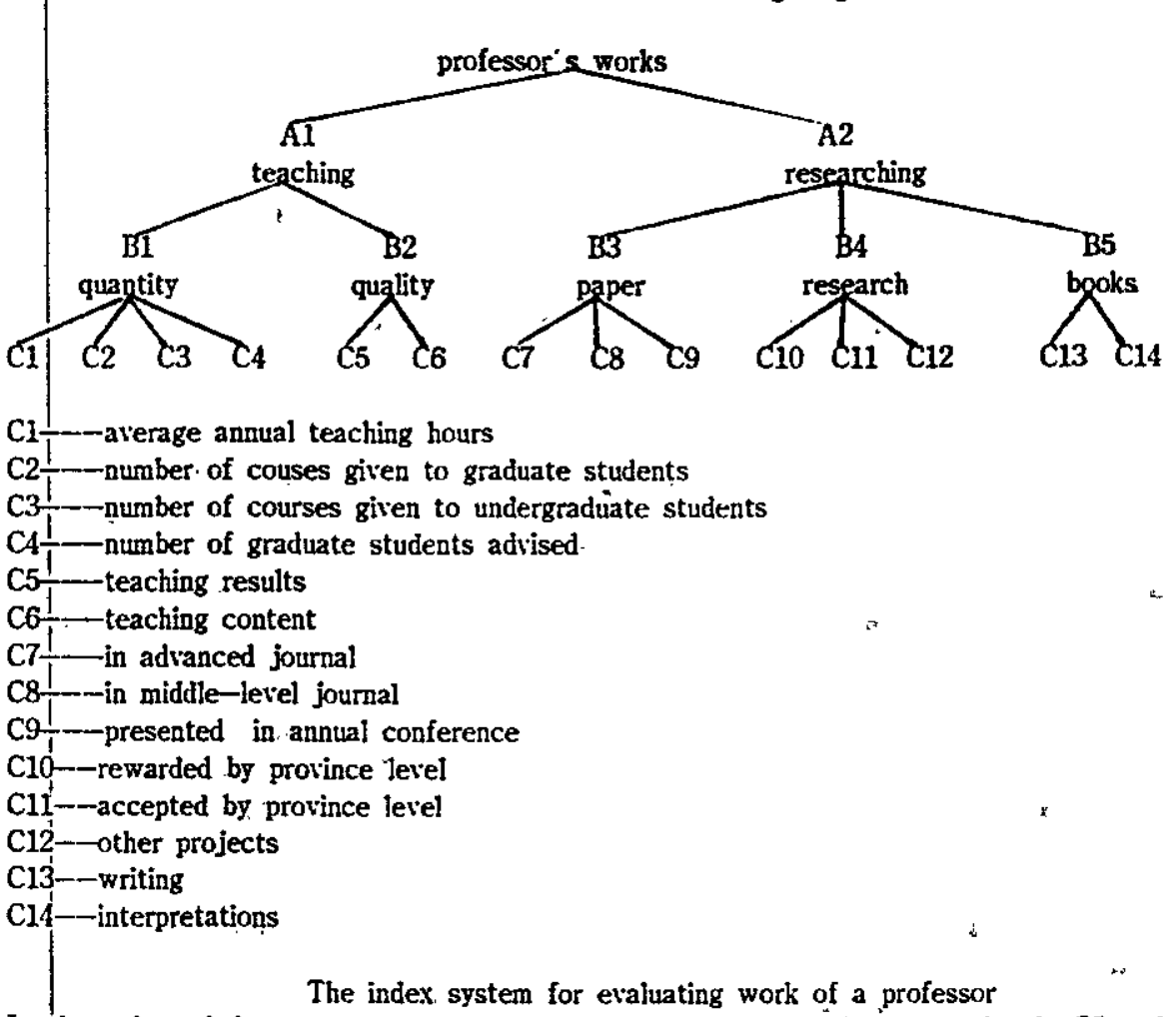

In the above index system. among the 14 single indexes in the lowest level. C5 and C6 are qualitative indexes the others are quantitative.

The indexes system for evaluating work of a staff members only a demonstration. different uniyersities or different departments in a university may add or remove some of the indexes which they think are suitable. But the basic idea is the same.

3. The Quantifying Process of the Indexes

According to the index system above to evaluate the-work of a staff; one netds to assess the indexes. This process can be accomplished by the following three steps.

11 From top to bottom to decide the relative importance of the factors in each level. in other 
words to assess the weights (W1, W2, ... W14) for each of the factors, $\mathrm{Ci}$ (i=1, 2. 14).

(2) To decide the evaluating vector (P1. P2, ... P14) where Pi is the evaluating value for factor $\mathrm{Ci}$.

(3) Using formular $\mathrm{F}=\mathrm{Z} \mathrm{Wi}-\mathrm{Pi}$ to determine evaluation index for each of the staff.

In step one, the AHP ( anal; tical Hierarchy Process) method invented by Professor L. Saaty was used.

4. The following is an example of using the evaluating method. Using AHP to determine the weights of the 14 indexes, the bij value are from an academic group headed by department chairman.

Level A. to compare the relative importance between teaching and research. From the given bij to determin the weights and calculate the largest characteristic value and standardized characteristic vector.

\begin{tabular}{c|cc} 
G & A1 & A2 \\
\hline A1 & 1 & 1 \\
A2 & 1 & 1
\end{tabular}

$$
\begin{aligned}
& \lambda \max =2 \quad C-I 1=0 \\
& w=(0.5,0.5)^{C}
\end{aligned}
$$

The weights related to upper

level $(\mathrm{al}, \mathrm{a} 2)=(0.5,0.5)$

Level B. First determine the relative importance of $\mathrm{B} 1$ and $\mathrm{B} 2$ to A1. Accoding to the given b12 one can have the deciding matrix (A1-B)

\begin{tabular}{c|cc}
$\mathrm{A} 1$ & $\mathrm{~B} 1$ & $\mathrm{~B} 2$ \\
\hline $\mathrm{B} 1$ & 1 & $1 / 3$ \\
$\mathrm{~B} 2$ & 3 & 1
\end{tabular}

$\lambda_{\max }=2, \quad \mathrm{C}-\mathrm{Il}=0$

$\mathrm{w}=(0.25,0.75)$

The weights relative to $A I$ is $\left(b_{1}^{2}+b_{2}{ }^{2}\right.$.

In the same way one can calculate the relative importance of $\mathrm{Bi}$ to $\mathrm{A} 2$,

\begin{tabular}{c|ccc}
$\mathrm{A} 2$ & $\mathrm{~B} 3$ & $\mathrm{~B} 4$ & $\mathrm{~B} 5$ \\
\hline $\mathrm{B} 3$ & 1 & 1 & 1 \\
$\mathrm{~B} 4$ & 1 & 1 & 2 \\
$\mathrm{~B} 5$ & $1 / 2$ & $1 / 2$ & 1
\end{tabular}

$\lambda \max =3$

$\mathrm{W}=(0.4,0.4,0.2), \mathrm{C}-12=0$

$\mathrm{R}-\mathrm{I2}=0.58, \mathrm{C}=\mathrm{R} 2=0<0.1$

The wieghts related to $A 2$ is $\left(b_{1}^{2}, b_{2}^{2}\right.$.

. $\left.\frac{b^{2}}{5}\right)=(0,0,0.4,0.4,0.2)$

\begin{tabular}{|c|c|c|c|}
\hline & $\begin{array}{l}\text { A1 } \\
0.5\end{array}$ & $\begin{array}{c}\mathrm{A} 2 \\
0.5\end{array}$ & weights related to level $A$ \\
\hline $\mathrm{B} 1$ & 0.25 & 0 & $\mathrm{bl}=0.125$ \\
\hline B2 & 0.75 & 0 & $\mathrm{~b} 2=0.375$ \\
\hline B3 & 0 & 0.4 & $b 3=0.2$ \\
\hline B4 & 0 & 0.4 & $b 4=0.2$ \\
\hline B5 & 0 & 0.2 & $b 5=0.1$ \\
\hline
\end{tabular}

Now we can calculate the weights of $\mathrm{Bi}$ related to level $\mathrm{A}$

$C=I=\Sigma a i=C-I i=0$ 


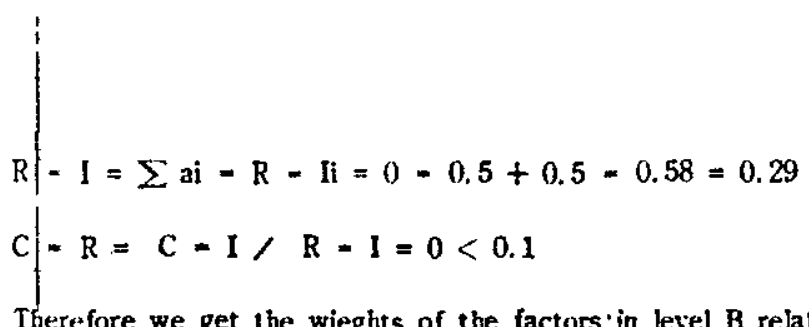

$=$ ( 0. 125, 0.375, 0.2. 1.2. 0.1).

Level $\mathrm{C}$. First calculate the relative weihts of $\mathrm{Ci}$ to $\mathrm{Bk}-(k=1,2, \ldots 5$ ) represented by (b . b , .... b). In other words one can set up the deciding matrix and then calculate their largest characteristic value and characteristic vectors.

\begin{tabular}{l|cccc}
$\mathrm{B} 1$ & $\mathrm{C} 1$ & $\mathrm{C} 2$ & $\mathrm{C} 3$ & $\mathrm{C} 4$ \\
\hline $\mathrm{C} 1$ & 1 & $1 / 5$ & $1 / 3$ & $1 / 5$ \\
$\mathrm{C} 2$ & -5 & 1 & 2 & 1 \\
$\mathrm{C} 3$ & -3 & $1 / 2$ & 1 & $1 / 2$ \\
$\mathrm{C} 4$ & 5 & 1 & 2 & 1
\end{tabular}

\begin{tabular}{c|cc}
$\mathrm{B} 2$ & $\mathrm{C} 5$ & $\mathrm{C} 6$ \\
\hline $\mathrm{C} 5$ & 1 & 3 \\
$\mathrm{C} 6$ & $1 / 3$ & 1
\end{tabular}

\begin{tabular}{c|ccc}
$\mathrm{B} 3$ & $\mathrm{C} 7$ & $\mathrm{C} 8$ & $\mathrm{C} 9$ \\
\hline $\mathrm{C} 7$ & 1 & 7 & 9 \\
$\mathrm{C} 8$ & $1 / 7$ & 1 & 2 \\
$\mathrm{C} 9$ & $1 / 9$ & $1 / 2$ & 1
\end{tabular}

\begin{tabular}{|c|ccc}
$\mathrm{B} 4$ & $\mathrm{C} 10$ & $\mathrm{C} 11$ & $\mathrm{C} 12$ \\
\hline $\mathrm{C} 10$ & 1 & 5 & 9 \\
$\mathrm{C} 11$ & $1 / 7$ & 1 & 2 \\
$\mathrm{C} 12$ & $1 / 9$ & $1 / 3$ & 1 \\
$\mathrm{~B} 5$ & $\mathrm{C} 13$ & $\mathrm{C} 14$ \\
\hline $\mathrm{C} 3$ & 1 & $1 / 5$ \\
$\mathrm{C} 14$ & 5 & 1
\end{tabular}

$\bar{\lambda}_{\max }=4.0042$

$\mathrm{w}=(0.00704,0.3684,0.1298,0.3684)$

$\mathrm{C}=\mathrm{R} 1=0.0014 / 0.9=0.0015<0.1$

The weights of $\mathrm{Ci}$ Related to.

$\mathrm{B} 1$ are $\left(\mathrm{C}_{1}^{1}, \mathrm{C}_{2}^{\frac{1}{2}}, \mathrm{C}_{3}^{\frac{1}{2}}, \ldots, \mathrm{C}_{14}^{\frac{1}{1}}\right)$

$=(0.0704,0.3684,0.1928,0.3684,0 \ldots \ldots 0)$

$$
\begin{array}{ll}
\lambda \max =2 & \mathrm{w}=(0.75 .0 .25) \\
\mathrm{C}=\mathrm{I} 2=0 & \mathrm{C}-\mathrm{R} 2=0
\end{array}
$$

The weights of $\mathrm{Ci}$ related to $\mathrm{B} 2$ are $(0,0,0,0,0.75,0.25,0, \ldots, 0)$

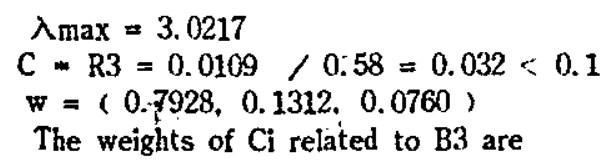

The weights of $\mathrm{Ci}$ related to $\mathrm{B} 3$ are $\left(c_{1}{ }^{3}, c_{2}^{3}, \ldots, c_{14}{ }^{3}\right)=(0,0,0,0,0,0$. $0.7604,0.7928,0.1312 .0 .07600, \ldots .0)$

$\lambda \max =3.0012$

$\mathrm{C}-\mathrm{R} 4=0.0006 / 0.58=0.001<1$

$\mathrm{W}=(0.7608,0.1576,0.0816)$

The weihts of $\mathrm{Ci}$ related to $\mathrm{B} 4$ are

$\left(c_{1}{ }^{4}, c_{2}^{4}, \ldots, c_{1}^{4}\right)=(0, \ldots, 0$.

$0.7604,0.1576,0.0816 ; 0,0)$

\section{$\lambda_{\max }=2$}

w $=(0.1667,0.8233)$

$C=12=0$

the weihgts of $\mathrm{Ci}$ related to $\mathrm{B} 5$ are

$\left.\left(c_{1}^{5}, c_{2}^{5} . \ldots, c_{14}^{5}\right)=0 . \quad .0 .0 .1667,0.8233\right)$. 
Now we can use the following table to calculate the weights of $\mathrm{Ci}$ rejated to level $\mathrm{B}$.

8

\begin{tabular}{|c|c|c|c|c|c|c|}
\hline & $\begin{array}{l}\text { B1 } \\
0.125\end{array}$ & $\begin{array}{c}\mathrm{B} 2 \\
0.375\end{array}$ & $\begin{array}{r}\text { B3 } \\
0.2\end{array}$ & $\begin{array}{r}B 4 \\
0.2\end{array}$ & $\begin{array}{r}\text { B5 } \\
0.1\end{array}$ & $\begin{array}{l}\text { weights of } \mathrm{Ci} \\
\text { related to level } \mathrm{B}\end{array}$ \\
\hline $\mathrm{Cl}$ & 0.0704 & 0 & 0 & 0 & 0 & 0.0088 \\
\hline $\mathrm{C} 2$ & 0.3684 & 0 & 0 & 0 & 0 & 0.0461 \\
\hline $\mathrm{C} 3$ & 0.1928 & 0 & 0 & 0 & 0 & 0.0241 \\
\hline $\mathrm{C}_{4}$ & 0.3684 & 0 & 0 & 0 & 0 & 0.0461 \\
\hline C5 & 0 & 0.75 & 0 & 0 & 0 & 0.2813 \\
\hline C6 & 0 & 0.25 & 0 & 0 & 0 & 0.0938 \\
\hline C7 & 0 & 0 & 0.7928 & 0 & 0 & 0.1586 \\
\hline C8 & 0 & 0 & 0.1312 & 0 & 0 & 0.0262 \\
\hline $\mathrm{Cg}$ & 0 & 0 & 0.076 & 0 & 0 & 0.0152 \\
\hline $\mathrm{ClO}$ & 0 & 0 & 0 & 0.7608 & 0 & 0.1503 \\
\hline $\mathrm{C} 11$ & 0 & 0 & 0 & 0.1576 & 0 & 0.0356 \\
\hline $\mathrm{Cl} 2$ & 0 & 0 & 0 & 0.0816 & 0 & 0.0141 \\
\hline $\mathrm{C} 13$ & 0 & 0 & 0 & 0 & 0.1667 & 0.0167 \\
\hline $\mathrm{C} 14$ & 0 & 0 & 0 & 0 & 0.8333 & 0.0833 \\
\hline \multicolumn{7}{|c|}{$\begin{aligned} C-I & =\sum \text { bi }-C-\mathrm{li} \\
& =0.125-0.0014+0.375=0+0.2-0.0107+0.2-0.0006+01-0=0 .(1) 25\end{aligned}$} \\
\hline$R=$ & $I=\Sigma b$ & $\mathfrak{i}=\mathrm{R} \mathrm{Ji}$ & .3445 & & & \\
\hline
\end{tabular}

From the table we get the weights for the factors in the $C$ level

8

$$
\begin{array}{llll}
\mathrm{C} 1=0.0088 & \mathrm{C} 2=0.0461 & \mathrm{C} 3=0.0241 & \mathrm{C} 4=0.0461 \\
\mathrm{C} 5=0.2813 & \mathrm{C} 6=0.0738 & \mathrm{C} 7=0.1586 & \mathrm{C} 8=0.0212 \\
\mathrm{C} 9=0.0152 & \mathrm{C} 10=0.1503 & \mathrm{C} 1=0.0356 & \mathrm{C} 12=0.0141 \\
\mathrm{C} 13=0.0167 & \mathrm{C} 14=0.0833 & &
\end{array}
$$

Now we get to step two. In determining $\mathrm{P}_{i}(\mathrm{i}=1,2, \ldots 14)$ for each of the faculty staff. the inserting value techniques can be used.

For the indexes with data, called quantitative indexes, in determining the Pi values one can first give 100 to the highest one and 0 to the lowest one. The others can be assessed by Linear ratio inserting method, and calculated from following formular

$$
P_{i=}^{k_{i}}\left(X_{i}^{K_{i}}-\min _{j}\left\{X_{i}\right\rangle / \operatorname{Max}_{j} \mid X_{j}^{j},-\operatorname{Min}_{j}\left\{X_{j}^{j}\right\}\right.
$$


Where $X_{1}^{1}$ represents the nark the $j$ th teacher gets on index $i$.

For examje, a staff get the evaluation marks on the fourteen indexes given in the following tablè

Thel evaluation marks on indexes of the professor(k)

\begin{tabular}{|c|c|c|c|c|}
\hline $\mathrm{Cl}_{\mathrm{I}}^{\mathrm{j}}$ & $\max _{i} X_{i}^{j}$ & $\min _{j} X_{i}^{j}$ & $X_{i}^{j}$ & $\mathrm{Pi}$ \\
\hline $\begin{array}{l}\text { c1 } \\
\text { c2 } \\
\text { c3 } \\
c 4 \\
\text { c7 } \\
\text { c9 } \\
\text { ci0 } \\
\text { ci1 } \\
\text { ci2 } \\
\text { ci3 } \\
\text { ci4 }\end{array}$ & $\begin{array}{r}2000 \\
10 \\
8 \\
7 \\
4 \\
10 \\
4 \\
3 \\
4 \\
30 \\
25\end{array}$ & $\begin{array}{r}600 \\
0 \\
0 \\
0 \\
0 \\
0 \\
0 \\
0 \\
0 \\
0 \\
0\end{array}$ & $\begin{array}{r}1500 \\
3 \\
6 \\
0 \\
2 \\
3 \\
1 \\
1 \\
1 \\
0 \\
2\end{array}$ & $\begin{array}{r}(1500-600 / 2000-600)=100=64 \\
(3-0 / 10-0)=100=30 \\
(6-0 / 8-0)-100=75 \\
(0-0 / 7-0)=100=0 \\
(2-0 / 4-0)=100=50 \\
(3-0 / 10-0)=100=30 \\
(1-0 / 4-0)=100=25 \\
(1-0 / 3-0)=100=33 \\
(1-0 / 4-0)=100=25 \\
(0-0 / 30-0)=100=0 \\
(2-0 / 25-0)=100=8\end{array}$ \\
\hline
\end{tabular}

For the indexes without data, or called qualitative indexes, when determining $\mathrm{Pi}$ vajue. We can use four levels to discribe their works. namely very good. good. acceptable, unacceptable. The results may be got from students feed back and peer revision among the staff. "The four levels can be quantified by $100,66,33$, and 0 . For instance the teacher $\mathrm{K}$ gets following in $\mathrm{C} 5$ and C6 1

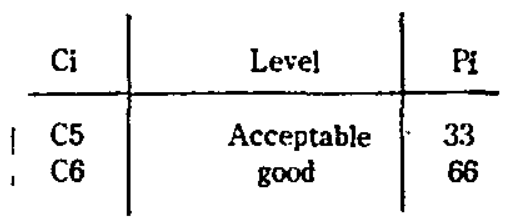

In this way, one can assess the $P$ values for a staff in. each of the evaluation factors. For the teacher $\mathrm{K}$ the $\mathrm{P}$ value are $, 64.30,75.0 .33,66,50.30 .25,0.33,25,0.8$ )

Now using the formular $\mathrm{F}=\sum \mathrm{Ci}-\mathrm{Pi}$ we can give the staff $\mathrm{s}$ work an evaluation Where $\mathrm{C}_{\mathrm{i}}$ is determined in step 1 and $P$ is assessed in step 2

Thel evaluation value given in the these steps could be used in analysis. comparison. and reference in different aspects.

5. The determination of Value Coefficient

In evaluating a teacher. or awarding his works. one should $\mathrm{nc}^{\circ}$ only look at the etaluation value calculated from above process, but also consider his or her value coefficient from the point of view of economics. According to value engineering point of view, in production sectors. both functional and value coeffecients of each part have to be considered There are also economic 
relations in educationel area as well. Although the possibility of using economic accounting in educational field is limited. it is also useful to appiy the economic lever in motivating people. Therefore, a similar value coeffeicient should be considered in evaluating the jobs of a staff. The formular $V=F / C$ can be used to determine the value coefficient. where $F$ is the value got from the evaluation above and $C$ is the salary of the staff.

In other words, we should consider both work (function) and salary (cost) in analyzing and evaluating a staff. especially when raising salary and distributing bonus. The value coeffeicient is important in evaluating a teacher $s$ job and it is even more important in considering staff at different leveis.

Evaluating the jobs done by a faculty member is only at the begining. This paper gives a reference system. there may be some problems. In fact it is very difficult to find a system suitable for every university and every academic field if it is not impossible. The index system should be changed ajong with time going as well. This paper gives an applicable quantitative method. But it needs to be improved in practice. The purpose of introducting value coefficient is to explore the possibility of using economic lever in educational sector.

\section{REFERENCE}

8

(1) Thomas L. Saaty, The Analytical Hierarchy Process. McGraw Hill Company 1980

(2) Xu Shubai. Introduction to. AHP. Tianjin University internal reference 1984

(3) Wang Zhihe Probing Several Problems in Education Evaluation Advance Research and Exploring

(4) A. Davilof. Economics for Higher Education. People's Publishing Cómpany

(5) Huang Yuxiang. Engineering Economics. Tongji University Publication 